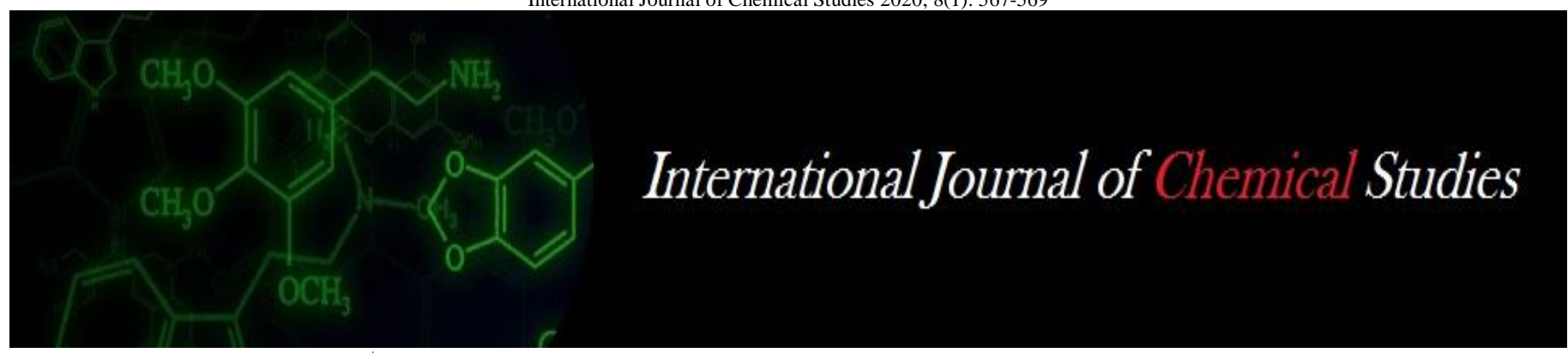

P-ISSN: 2349-8528

E-ISSN: 2321-4902

IJCS 2020; 8(1): 567-569

(C) 2020 IJCS

Received: 23-11-2019

Accepted: 25-12-2019

Dr. Shashi Singh

HOD Home science, K.S. Saket P.G. College, Ayodhya, Uttar Pradesh, India

\section{Immunization Status of pre-school for female children in Ayodhya (Faizabad) District Uttar- Pradesh}

\section{Dr. Shashi Singh}

\begin{abstract}
The paper deals with a immunization status of preschool female children with the help of multistage sampling techniques for this purpose sampling techniques suggested by Henderson and Sunderson was adopted for Faizabad district. Taking both rural and urban population .A pretested and predesigned scheduled was employed for this purpose.
\end{abstract}

Keywords: The immunization status was formed significantly associated with the residential status, mothers education and socio-economic status of the family.

\section{Introduction}

The global eradication of small pox attracted the health personnel to think for the control of the six major killing diseases, such as diphtheria, pertussis neonatal and maternal tetanus, poliomyelitis, tuberculosis and measles three are the immunoprophylactable disease, and can be prevented by proper and potent vaccines in adequate doses. Keeping in view these aspects expanded programme in Immunization (EPI) in May 1974 (in India 1978) and Universal Immunization programme (UIP) in 1984 were launched in member countries of world health organization, but in India UIP was implemented in November $1985^{[1]}$. It was considered that till the year 1990, these major killing diseases will be completely eradicated ${ }^{[2]}$. But it is very sad that the Immunization coverage in urban areas lies between $30 \%$ to $40 \%$ and in rural areas, it was limited to $10 \%$ to $20 \%$ only till the end of $1990^{[3]}$. The CSSM review (GOI, 1993) mentioned the level of child immunization as $85.8 \%$ in the year $1993^{[4]}$.

\section{Material and Methods}

On the basis of multistage sampling technique two localities of rural and urban areas were selected. Six hundred eighty female children; three hundred forty each from rural and urban areas were considered the sample of the present study. Adhering to the technique developed by Handerson and Sunderson (1982) ${ }^{[5]}$, the sample children were identified. Interview cum questionnaire method was employed to collect the desire information's. The questionnaire included general information's regarding mother and pre-school female children along with the specific information desire for the study purpose.

The socio-economic status of the family was ascertained on the basis of Prasad's Social Classification [6,7,8], while the formal education received by the children's mother was considered as mother's literacy status.

The immunization status of family children was recorded by interviewing the mothers, noticing BCG scar mark, ascertaining the record for immunization card, if available. The children who had received all the four vacancies i.e. BCG, OPV, DPT and measles and completed all doses of vaccines were classified as fully immunized; those children who had missed any one of polio, DPT, BCG or measles and had not completed all doses were classified into partially immunized. Those children who had not taken any one of the above vacancies were classified under immunized category, The immunization access rate was determined on the basis of number of children who had taken full or partial dose of any immunization.
Corresponding Author: Dr. Shashi Singh HOD Home science, K.S. Saket P.G. College, Ayodhya, Uttar Pradesh, India 


\section{Result and Discussion}

The present communication relates to the immunization coverage of the pre-school female of Faizabad district. It is evident that the immunization access rate (Table No. $1 \&$ Graph 1) among the pre-school female children was $73.68 \%$, were than half of the children $(52.94 \%)$ were fully immunized against tuberculosis, polio, diphtheria, pertussis, tetanus and measles. But $20.74 \%$ children could not take the full course of immunization due to various reasons.

These reason included sickness of the child or mother, the child was not present in the house on the day of immunization and the immunization center was far away from the residence. It is very disappointing that $26.32 \%$. Female children did not take even a single dose of any kind of immunization.

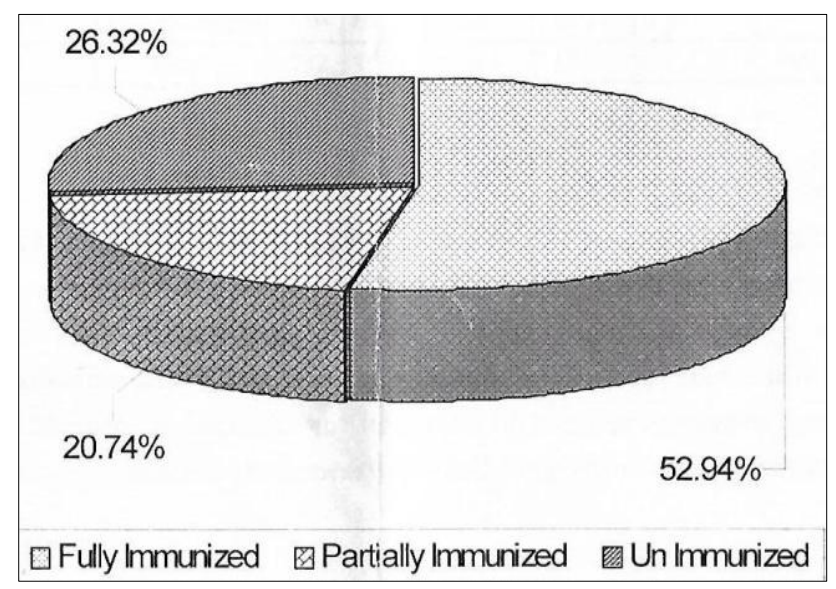

Graph 1: Immunization Status of Pre-school Female Children

The GOI is trying for $100 \%$ immunization till 2000 A D though it's UIP, but seems failure in Faizabad district of uttar Pradesh. The extended coverage evaluation survey of CSSM in Ghazipur and jaunpur district (1995) of Uttar Pradesh showed very low figures of $48.82 \%$ and $35.50 \%$ of fully immunized children between the ages of 12 to 23 month ${ }^{[9]}$.
According to residential status, the contributions of fully, partially and unimmunized children in urban areas were $61.47 \%, 17.06 \%$ and $21.47 \%$ respectively, against $44.41 \%$, $24.41 \%$ and $31.18 \%$ female children in rural areas (Table $1 \&$ Graph No.-2).

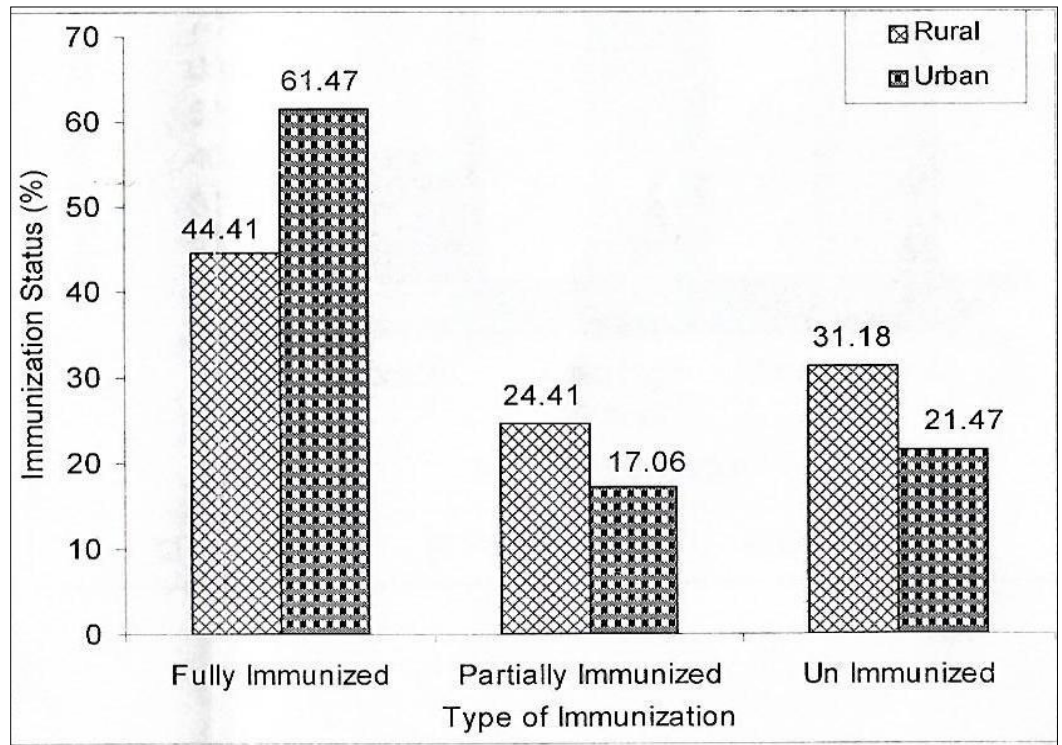

Graph 2: Immunization Status of pre-school female children according to their residence

The statistical analysis witnessed that the immunization status of rural children was significantly lower $\left(\mathrm{X}^{2}=19.861, \mathrm{DF}=2\right.$, $P<0.001)^{* * *}$ than their urban counterparts. The low accessibility of health services in the rural area and low knowledge status of rural mothers regarding immunization are responsible for this feature ${ }^{1}$. The literate mother ${ }^{[9]} \mathrm{s}$ had good knowledge of health services available through PHC s, MCH sub centre's or from district hospital or health centre's or private practitioners The immunization status was found increasing (Table No. 2 and Graph No.3) with the advancement of mothers [9] education. On its contrary illiterate mothers were unable to provide immunization to their children. The immunization access rate was to the tune of cent percent belong to intermediate and above status of mother ${ }^{[9]} \mathrm{s}$ education, followed by upto high school $(84.86 \%)$ and illiterates $(37.07 \%)$.

The statistical analysis supported the significant role of mother's education $\left(\mathrm{X}^{2}=378.979, \mathrm{DF}=4, \mathrm{P}<0.001\right) * * *$ towards their children immunization. Though the immunization massages are regularly communicated through T.V., Radio, hoarding, poster and advertisement in magazines, periodical \& newspapers, still the illiterate mother did not take care of these programmes due to negligence and unawareness towards the importance of immunization 
provided to the children. In addition the mothers do not give due consideration to the female child, and they remain the neglected part of the community. On the other hand literate mothers are able to read the massages and understand the utility of immunization programme communicated through various audios-visuals and print literature ${ }^{[1]}$. In addition the literate mothers are broad minded, and they are fully aware toward girl child to provide her equal opportunity in every aspect of the life.

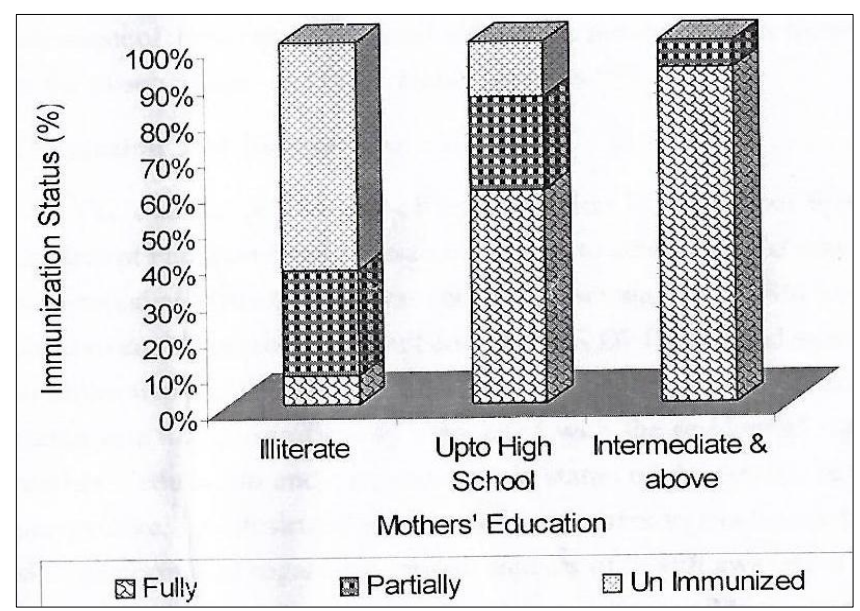

Graph 3: Role of Mother's Education on Immunization Status

The other factor which influenced the immunization status of the pre-school female child was socio-economic status of the family (Table no.3 Graph No. 4).

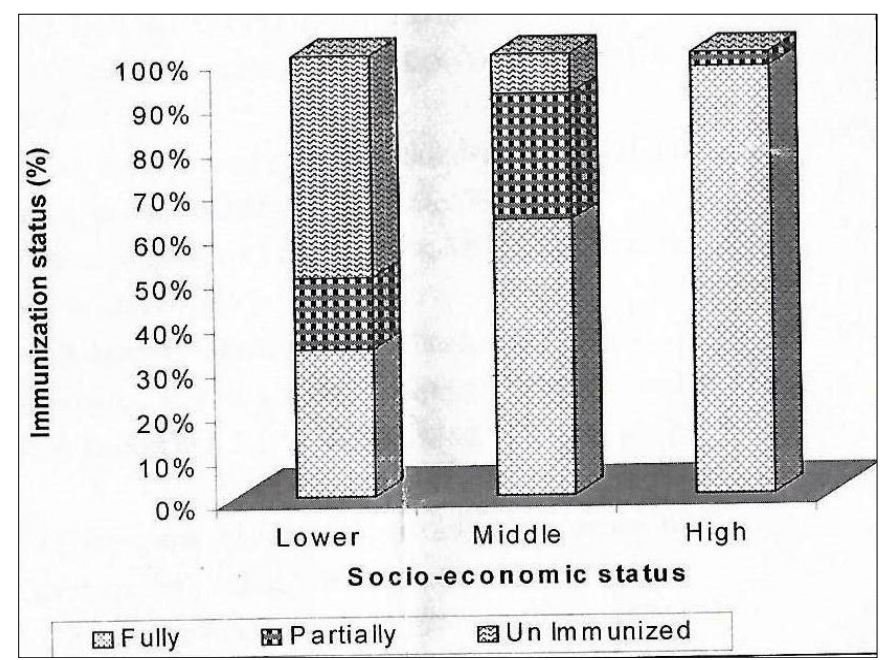

Graph 4: Immunization status according to socio-economic status

It was observed that the contribution of fully and partially immunized female children were $33.33 \%$ and $16.16 \%$ in low social hierarchy, while $62.26 \%$ and $28.62 \%$ female children belonging to middle class; and $69.92 \%$ and $3.08 \%$ female children belonging to high social class were found fully and partially immunized. The statistical analysis evidenced, significant positive association between immunization status of the female children $\left(\mathrm{X}^{2}=191.197, \mathrm{DF}=4, \mathrm{p}<0.001\right) * * *$ and their socio-economic status, though the immunization service is provided free of cost.

This finding delineates that the high status families have good knowledge of immunization services and practiced in the similar manner, because the rich and affordable families have radio and T.V. like communication facilities, which positively affects the health culture and behaviour of the community.
The finding of present study correspond to the observation made by various workers ${ }^{[10,11]}$.

\section{Conclusion and Suggestion}

The over all access of immunization in pre-school female children of Faizabad district was found similar to other studies conducted in surrounding district, but it was very disappointed that $20.74 \%$ female children could not receive the full dose BCG, DPT, Polio and measles, in addition to $26.32 \%$ subject of immunized status. The immunization status was found significantly associated with the residential status, mother's educations and socio-economic status of the family. In this perspective, it is desirable to educate the mothers to ameliorate their skill performance regarding various aspects of health awareness and practices for maintaining optimum health status of the children in general \& female children in particular.

\section{References}

1. Gupta JNP. Management information and economic System in vaccine preventable disease control programme of Varanasi. Ph.D. Thesis department of preventive \& Socio Medicine. Institute of medical Science, BHU, Varanasi, 1994.

2. Park JE, Park K. Text Book of preventive \& Social Medicine. Jabalpur. Bamarasi Das Bhanot (Pub), 1989, 492.

3. Hindustan Times. 190 Quoted by Gupta, JNP, eco. cit.

4. GOI. National Health Policy- MCH goals, CSSM review No. 9; 1. Ministry of Health and Family Welfare, New Delhi, 1993.

5. Handerson RH, Sunderson T. Cluster sampling to assess immunization coverage: A review of experience with a simplified sampling method. Bull. WHO. 1982; 60(2):253-60.

6. Prasad BG. Social Classification of Indian families. I: Ind. Med. Assoc. 1961; 37:250-251.

7. Chandra J, Ahmad SH. Prasad's social classification of Indian families, Updated, Indian Pediatr. 1987; 24:68990.

8. Dainik Jagran. (Varanasi Edition): $1^{\text {st }}$ feb., 1998. All india consumer price index for December, 1987.

9. Mahapatra SC, Singh SP, Gupta JNP, Tendon J. Extended coverge evaluation survey of CSSM in districts Ghazipur and jaunpur of U.P.: A report ind. J prev. \& soc. Med. 1995; 26(3-4):78-81.

10. Bhandari B, Mandowara SL, Gupta GK. Evaluation of vaccination coverage. Ind. J Ped. 1990; 57:197-201.

11. Mahapatra SC, mahapatra P, Kumar A. Roie of mass media on health Awareness of population. Ind. J Comm. Hith. 1990; 6(1):24-28.

12. Subhash Arya C. Infant and Child Care. Vikash PubliShing House Pvt. Ltd. New Delhi. 